
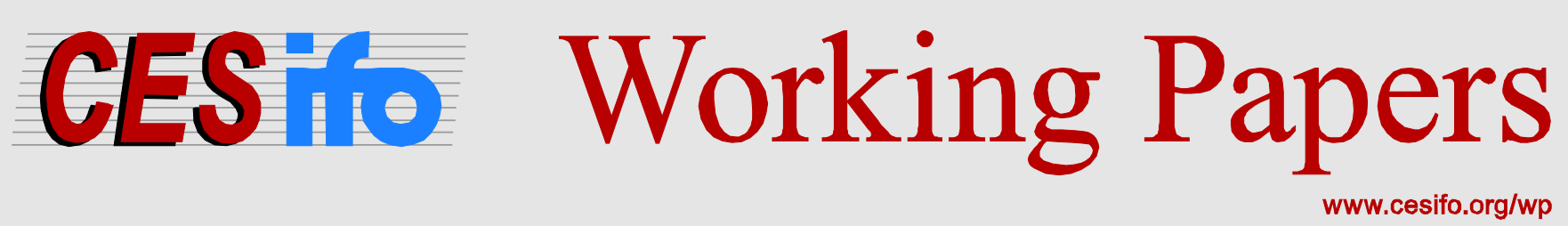

\title{
Can Risk-taking Preferences be Modified? Some Experimental Evidence
}

\author{
Alison L. Booth \\ Patrick J. Nolen
}

CESIFO WORKING PAPER NO. 4751

CATEGORY 13: BEHAVIOURAL ECONOMICS

APRIL 2014

An electronic version of the paper may be downloaded

- from the SSRN website:

- from the RePEc website:

- from the CESifo website:

WWW.SSRN.com

www.RePEc.org

www.CESifo-group.org/wp

\section{CESifo}




\title{
Can Risk-taking Preferences be Modified? Some Experimental Evidence
}

\begin{abstract}
We summarise our two sets of controlled experiments designed to see if single-sex classes within coeducational environments modify students' risk-taking attitudes. In Booth and Nolen (2012b), subjects are in years 10 and 11, while in Booth, Cardona-Sosa and Nolen (2014), they are first-year university students randomly assigned to single-sex and coed classes. While on average females are significantly less likely than men to make risky choices, on exposure to single-sex environments they behave the same as the males. Thus part of the observed gender difference in behavior under uncertainty found in previous studies might reflect social learning rather than inherent gender traits.
\end{abstract}

JEL-Code: C900, C910, C920, J160, D010, D800, J160, J240.

Keywords: gender, risk preferences, single-sex groups, cognitive ability.

\author{
Alison L. Booth \\ Crawford School of Public Policy \\ J.G. Crawford Building, \#132 \\ Lennox Crossing \\ The Australian National University \\ Australia-Canberra ACT 0200 \\ alison.booth@anu.edu.au
}

\author{
Patrick J. Nolen \\ Department of Economics \\ University of Essex \\ Wivenhoe Park \\ United Kingdom - C04 3SQ Essex \\ pjnolen@essex.ac.uk
}

Revised March 2014

This address was presented at the workshop entitled, "The Determinants of Gender Gaps: Institutional Design and Historical Factors”, at CESifo's $14^{\text {th }}$ Venice Summer Institute, Venice, July 2013. Alison Booth thanks CESifo and the conference organisers and editors for their hospitality, and Booth and Nolen thank the anonymous referee for his or her comments. 


\section{Introduction}

Discussions of the origin of gender gaps in economic outcomes sometimes raise the issue of whether productivity-enhancing characteristics are gender-specific or are instead developed by cultural values within the community. For example, have men evolved to be innately more risktaking than women or have they become that way in part through cultural pressures? In the nature versus nurture debate about male and female preferences and outcomes, where do we stand as economists? In our experimental work, we have tried to take a small step forward in this regard, and this paper will outline some of this work.

Women are increasingly employed in the market sector of the economy and they are increasingly enrolling in degree fields that have been largely male. Yet there are still many areas where women are under-represented. Examples are found in the highest levels of mathematics, the physical sciences, and engineering (NAS 2006). This is in spite the fact that, in many countries, more women now attend university than men. ${ }^{2}$ Furthermore, in the US there is a gender gap in standardized mathematics tests scores. ${ }^{3}$ This is especially pronounced at the top of the distribution (Ellison and Swanson, 2010).

It has been suggested that there might be gender differences in risk aversion, feedback preferences or taste for competition, and that these might explain gender differences in observed educational and labour market outcomes. For example, obtaining promotions and pay raises often involves competition, and it may be that women do not like to compete but men do. A relatively recent and rapidly growing literature attempts to investigate - using either survey or experimental data - if women and men differ systematically in some psychological characteristics that might explain the fact that women are under-represented in high-paying jobs and high-level occupations. If so, then the suggestion is that - once these differences are controlled for perhaps the gender pay gap will disappear from empirical estimates.

\footnotetext{
${ }^{2}$ In the US in the 1960s there were 1.55 males for every female undergraduate but by 2003 there were 1.30 females for every male undergraduate (Goldin et. al. 2006). A similar ratio is found in Australia (Booth and Kee, 2011).

${ }^{3}$ There is a gender gap in standardized mathematics tests that varies across countries (Else-Quest et. al. 2010, Guiso et. al 2008) and some argue it may not be large enough to be of any practical importance (Hyde et. al. 2008). However Fryer and Levitt (2010) document a substantial gender gap in mathematics in the US. After six-years of education, students have a $\mathbf{0 . 2}$ of a standard deviation gender gap in test scores. This gap is roughly half as large as the black-white test score gap.
} 


\section{Psychological factors and survey-based evidence}

What does survey-based evidence have to say about the role of psychological factors in affecting gender wage gaps? Clearly the use of contemporaneous survey-based measures of risk-aversion, self-esteem and competitive or collaborative behavioural traits is dogged by potential endogeneity. However, personality variables are incorporated into the survey-based analysis of, inter alia, Goldsmith et al. (1997), Bowles et al. (2001), and Mueller and Plug (2004). Using NLSY data, Goldsmith et al. (1997) show that personality variables as well as human capital are correlated with wages, but they do not investigate the gender dimension. However, Mueller and Plug (2006) do examine the gender dimension using a Wisconsin-based survey. While their psychological variables are contemporaneous with measured earnings, they nonetheless find interesting correlations between measures of personality and earnings. Manning and Swaffield (2008) avoid the endogeneity issue by using predetermined psychological information - mainly measured at age 16 - from the British Cohort Study to estimate gender wage gaps at age 30. They find that, on labour market entry, there is no gender wage gap for otherwise identical, fully "work-committed" women and men (those with no children, no intention of having children, and with continuous full-time work experience). However, by age 30 there remains a substantial unexplained gap: women who have continuous full-time employment, have had no children and express no desire to have them, earn about 8 log points less than equivalent men after 10 years in the labour market. Manning and Swaffield then investigate the role of psychological variables in explaining this, focusing on risk attitudes, competitiveness, self-esteem, 'other-regarding', and career-orientation. ${ }^{4}$ The psychological variables are found to explain an 'upper-bound' of 4.5 log points of the gender wage gap.

Some of these survey-based measures of psychological factors are rather indirect. Moreover it is not easy to find measures of psychological factors that are genuinely predetermined or that do not change over time. It is therefore of great interest to see if alternative methods of data collection can shed light on whether or not there are significant gender differences in psychological factors that could explain gender pay gaps and glass ceilings.

\footnotetext{
${ }^{4}$ Risk attitudes are proxied by wearing a seat-belt, completion of a first-aid course, smoking and drinking and the like, while competitiveness relates to sporting and game activities. The authors are disarmingly frank about the difficulties associated with using some of these proxies and the 'tangential' nature of some of the variables.
} 


\section{Experimental studies and personality differences}

\subsection{Overview}

Women and men may differ in their propensity to choose a risky outcome because of innate preferences or because pressure to conform to gender-stereotypes encourages individuals to modify their innate preferences. In the remainder of this paper, we outline two sets of our experiments investigating the extent to which environmental factors or culture might determine gender differences in economic preferences. ${ }^{5}$ These experiments were, among other things, designed to elicit preferences for risk-taking.

In these experiments, we explored the role that culture might play in affecting economic preferences. ${ }^{6}$ Our first set of experiments used secondary school students as subjects, while the second set of experiments used first-year university students. It is well-known that the academic achievement of girls and boys responds differentially to co-education, with boys typically performing better and girls worse than in single-sex environments (Kessler et al., 1985; Brutsaert, 1999). Moreover, psychologists argue that the gendered aspect of individuals' behaviour is brought into play by the gender of others with whom they interact (Maccoby, 1998).

Our main conjecture in these two sets of experiments was that a same-sex environment may modify preferences in an economically important way. Studies show that there may be more pressure for girls to maintain their gender identity in schools or colleges where boys are present than for boys when girls are present (Maccoby, 1990; Brutsaert, 1999). In a coeducational environment, girls are more explicitly confronted with adolescent subculture (such as personal attractiveness to members of the opposite sex) than they are in a single-sex

\footnotetext{
${ }^{5}$ Recent laboratory-based experiments show that, when given the choice of whether or not to enter tournaments, women do indeed 'shy away from competition' while men might choose to compete too much (see inter alia Gneezy, Niederle and Rustichini, 2003; Datta Gupta, Poulsen, and Villeval, 2005; Niederle and Vesterlund, 2007). Understanding why women seem less inclined than men to compete may provide insight into why a gender gap still exists in the workplace.

${ }^{6}$ For a paper looking at the impact on competition of another cultural variable - whether a society is patriachal or matrilineal - see Gneezy, Leonard and List (2009).
} 
environment (Coleman, 1961). This may lead them to conform to boys' expectations of how girls should behave to avoid social rejection (American Association of University Women, 1992). If non-competitive behaviour or risk avoidance is viewed as being a part of female gender identity while competitiveness or risk-seeking is a part of male gender identity, then being in a coeducational school or college environment might lead girls to make less competitive and less risky choices than boys. ${ }^{7}$

\subsection{First experiment}

\subsubsection{Experimental design}

We noted above that women and men may differ in their propensity to choose a risky outcome because of innate preferences or because pressure to conform to gender-stereotypes encourages them to modify their innate preferences. Single-sex environments are likely to modify students' risk-taking preferences in economically important ways. To test this, in our first set of controlled experiments, we designed an experiment in which subjects were given an opportunity to choose a risky outcome - a real-stakes gamble with a higher expected monetary value than the alternative outcome with a certain payoff - and in which the sensitivity of observed risk choices to environmental factors could be explored.

In Booth and Nolen (2012b), we investigated if individuals' risk preferences are affected by (i) the gender composition of the group to which they were randomly assigned ${ }^{8}$, and (ii) the gender mix of the school they attended. The latter represented longer-run nurturing experiences, while the former captured short-run environmental effects. ${ }^{9}$ Our 260 subjects, from

\footnotetext{
${ }^{7}$ There is a lively debate in the literature about single-sex schooling, as recent articles in Science indicate. See for example Halpmen et al (2011) and the collection of irritated responses that followed in the January 2012 issue. To our knowledge, our second set of experiments - one of which is discussed in this present paper - are the only papers to investigate the impact of university-level single-sex classes at on economic outcomes.

${ }^{8}$ While this group effect has been explored in previous work by Gneezy et. al. (2003), Niederle and Yestrumskas (2007) and Datta Gupta et. al. (2005), those studies focused on competitive tasks. They did not investigate risk attitudes nor did they explore how risk preferences may change over time - the main focus of our investigation.

${ }^{9}$ In a companion paper, Booth and Nolen (2012a) investigated how competitive behaviour (including the choice between piece-rates and tournaments) is affected by single-sex experimental peer-groups and single-sex schooling. In this present paper we discuss only that part of each of our experiments dealing with risk.
} 
eight publicly funded single-sex and coeducational schools in the counties of Essex and Suffolk in the UK, were asked to choose between a real-stakes lottery and a sure bet.

Four of the schools were single-sex. The students were from years 10 or 11 , and their average age was just under 15 years. After being bused to the University of Essex, students from each school were randomly assigned into 65 groups of four. Groups were of three types: all-girls, all-boys or mixed. Mixed groups had at least one student of each gender and the modal group comprised two boys and two girls. The composition of each group - the appropriate mix of single-sex schools, coeducational schools and gender - was determined beforehand. Thus only the assignment of the 260 girls and boys from a particular school to a group was random. The school mix was two coeducational schools from Suffolk (103 students), two coeducational schools from Essex (45 students), two all-girl schools from Essex (66 students) and two all-boy schools from Essex (46 students).

The payments (both the show-up fee of $f 5$ plus any payment from performance in the randomly selected round) were in cash and were hand-delivered in sealed envelopes (clearly labelled with each student's name) to the schools a few days after the experiment. The average payment was f7. In addition, immediately after completing an Exit Questionnaire (eliciting demographic information), each student was given a bag containing a soft drink, a packet of crisps and a bar of chocolate.

In the county of Suffolk, there are no single-sex publicly funded schools. In the county of Essex, the old 'grammar' schools remain, owing to an accident of political history. ${ }^{10}$ These grammar schools are single-sex and, like the coeducational schools, are publicly funded. It is highly unlikely that students themselves actively choose to go to the single-sex schools. Instead Essex primary-school teachers, with parental consent, choose the more able Essex children to sit

\footnotetext{
10 In the UK, schools are controlled by local area authorities but frequently 'directed' by central government. Following the 1944 Education Act, grammar schools became part of the central government's tripartite system of grammar, secondary modern and technical schools (the latter never got off the ground). By the mid-1960s, the central Labour government put pressure on local authorities to establish 'comprehensive' schools in their place. Across England and Wales, grammar schools survived in some areas (typically those with long-standing Conservative boroughs) but were abolished in most others. In some counties, the grammar schools left the state system altogether and became independent schools; these are not part of our study. However, in parts of Essex, single-sex grammar schools survive as publicly funded entities, whereas in Suffolk, they no longer exist.
} 
for the Essex-wide exam for entry into grammar schools. ${ }^{11}$ Parents must be resident in Essex for their children to be eligible to sit the entrance examination (the 11+). However, residential mobility across regions is very low in Britain (Boheim and Taylor, 2002). To attend a grammar school, a student must apply and then attain above a certain score, which varies from year to year and from school to school. Therefore, students at the single-sex schools are not a random subset of the students in Essex, since they are selected based on measurable ability at age 11 . To make sure the students from Suffolk were comparable to those from Essex, we recruited the top students; only students from the advanced math classes were invited to participate in the experiment.

In that part of the experiment directed at risk, we had girls and boys chose between Option 1 ( $f 5$ for certain) and Option 2 (flip a coin and get $f 11$ if the coin came up heads or $f 2$ if the coin came up tails). Clearly the expected monetary value of the risky option, Option 2, exceeds the certain outcome in Option 1. The dependent variable in our analysis took the value one if the individual chose to enter the lottery and zero otherwise. The implied coefficient of relative risk version (CRRA) was 0.8 . We imposed the coefficient of relative risk aversion because we had limited resources and a limited number of rounds. Table 1 below shows the marginal effects of those probit regressions.

\subsubsection{Results}

The first column of Table 1 - reproduced from Booth and Nolen (2012b) - shows that, on average, girls choose to enter the lottery 16 percentage points less than boys. The sign and significance of this coefficient is consistent with other work looking at gender and risk aversion and suggests that, in our sample, female students are also more risk averse than male students. This provides evidence for the hypothesis that women are, on average, more risk averse than men.

The reader might also be interested to know that part of observed risk differences between men and women can be manipulated by framing operations, as shown in Booth and

\footnotetext{
${ }^{11}$ If a student achieves a high enough score on the exam, s/he can attend one of the 12 schools in the Consortium of Selective Schools in Essex (CSSE). The vast majority of these are single-sex. The four single-sex schools in our experiment are part of the CSSE.
} 
Nolen (2012c). While this is an interesting finding that we hope will be further investigated in future work, this is not the focus of this paper. Here we are more interested in environmental factors rather than in the way the question eliciting risk preferences is framed. ${ }^{12}$

Next, we wanted to investigate if the gender differences alter when environmental factors reflecting nurture are incorporated into the probit estimation. The specification in column [2] adds controls for school type and experimental group composition. In this specification, the gender gap becomes even more pronounced - girls in coed schools choose to enter the lottery 36 percentage points less than boys from coeducational schools. Furthermore, we have evidence that nurture has an effect on risk preferences. First, the coefficient for being in an all-girls group is statistically significant and positive: girls randomly assigned to all-girl groups are more likely to choose to enter the lottery. Because our estimates show that girls assigned to single-sex peer groups are less risk averse than those who are assigned to mixed-gender groups, evidence is provided in support of our hypothesis that girls in same-gender experimental groups are less risk averse than girls in mixed-gender experimental groups. ${ }^{13}$ Notice that the samegender peer group is only affecting girls; the all-boys coefficient is insignificant.

Second, the single-sex school coefficient is statistically insignificant but the coefficient to single-sex schooling interacted with female is significant and positive. Therefore school background only affects the risk preferences for girls at this level of risk aversion, and has no effect on boys. The risk preferences of boys are not affected by either environmental variable, whereas the risk preferences of girls are significantly affected by both environmental factors.

\footnotetext{
12 Risk theories typically assume individuals make risky choices using probability weights that differ from objective probabilities. Recent theories suggest that probability weights vary depending on which portion of a risky environment is made salient. Booth and Nolen (2012c) used experimental data to show that salience affects young men and women differently. We found that men are significantly more likely than women to switch from a certain to a risky choice once the upside of winning is made salient, even though the expected value of the choice remains the same. (The type of class - single-sex or coeducational - had no effect on the probability of being affected by salience.) Quite why this might occur remains a topic for future research. However, our finding of gender differences in the probability of being affected by salience has an additional implication, namely part of observed risk differences between men and women can be manipulated by framing operations.

${ }^{13}$ The all-girls coefficient is robust to different types of analysis. For instance, if regressions are run on sub- samples comprising only students from coed schools, or only students from single-sex schools, the all-girl coefficient is still significant. Thus, there is a positive effect of being in an all-girls group for each type of student. Furthermore, if dummy variables for mixed-gender groups with three or two boys are used as controls, the significance of the allgirls coefficient does not go away.
} 
We now use the estimated coefficients in Column [2] to compare a girl from a coed school placed in an all-female group with a coed male (the base group). To do this, we add the coefficient of the female dummy variable to that of the all-female class: this gives $(-0.36+0.12)=-$ 0.24. This is not statistically different from zero. Next we consider a girl from a single-sex school who is in an all-female group for the experiment, and compare her with the base-group coed male. Here we now need to include the coefficient on single-sex and female*single-sex as well. The magnitude of the effect is thus $(-0.24+0.33-0.13)=-0.04$. This is also not statistically different from zero.

Column [3] of Table 1 adds in some 'ability' controls, namely the score students obtained in the mandatory completion of mazes in Rounds 1 and 2 of the experiment. These rounds were paid on the basis of piece rates in Round 1 and a tournament in Round 2. These 'ability' variables are denoted as the number of mazes correctly completed in Round 1 (R1) and the difference between the number of mazes correctly completed in Rounds 1 and 2 (R2-R1). The estimates of interest - gender, group-type and single-sex schooling and its interaction with gender - are robust to the inclusion of these variables. Column [4] adds in a number of additional controls that are listed in the note under the table (and whose coefficients are not included in this table). Again the results of interest are robust to this change of specification. 
Table 1: Dependent Variable $(0,1)$ If Student Chose Option 2 in the Lottery

\begin{tabular}{|c|c|c|c|c|}
\hline COEFFICIENT & {$[1]$} & [2] & [3] & [4] \\
\hline \multirow[t]{2}{*}{ Female $(=1)$} & $-0.16 * * *$ & $-0.36 * * *$ & $-0.37 * * *$ & $-0.34 * * *$ \\
\hline & {$[0.05]$} & [0.07] & {$[0.07]$} & {$[0.11]$} \\
\hline \multirow[t]{2}{*}{ Single-Sex $(=1)$} & & -0.13 & -0.13 & -0.06 \\
\hline & & [0.10] & {$[0.10]$} & [0.18] \\
\hline \multirow[t]{2}{*}{ Female $*$ Single-Sex } & & $0.33 * * *$ & $0.33^{* * *}$ & $0.30^{* *}$ \\
\hline & & {$[0.06]$} & {$[0.06]$} & {$[0.12]$} \\
\hline \multirow[t]{2}{*}{ All-Girls Group (=1) } & & $0.12 *$ & $0.12 *$ & $0.14 * *$ \\
\hline & & [0.06] & {$[0.06]$} & {$[0.06]$} \\
\hline \multirow[t]{2}{*}{ All-Boys Group (=1) } & & -0.05 & -0.04 & -0.05 \\
\hline & & [0.10] & [0.10] & {$[0.11]$} \\
\hline \multirow[t]{2}{*}{ Maze Score R1 } & & & -0.01 & \\
\hline & & & {$[0.03]$} & \\
\hline \multirow[t]{2}{*}{ Maze Score R2 - R1 } & & & 0.02 & \\
\hline & & & {$[0.02]$} & \\
\hline Marginal Effect for Female $=$ & & -0.07 & -0.06 & -0.03 \\
\hline Single-Sex $=$ Female $*$ Single-Sex $=1$ & & [0.05] & [0.05] & {$[0.06]$} \\
\hline Observations & 260 & 260 & 260 & 260 \\
\hline
\end{tabular}

\subsubsection{Checking for Endogeneity}

A student's attendance at a single-sex school is likely to be influenced by her ability as well as by the choices of her parents or teachers. ${ }^{14}$ Therefore students from single-sex schools may not be a random subset of the students from Essex (although it should be remembered that we asked only top students from coeducational schools to participate in the experiment). To test the robustness of the female, single-sex coefficient, we undertook a number of sensitivity checks. These are are reported in full in Booth and Nolen (2012b), and here we only give a brief

\footnotetext{
${ }^{14}$ As noted earlier, Essex primary-school teachers and parents choose which children sit for the Essex-wide exam for entry into grammar schools. Parents must be resident in Essex for their children to be eligible to sit the entrance examination (the 11+).
} 
overview of the results. For example, we compared single-sex students to a different comparison group: students from Suffolk plus students in Essex who took the 11+ exam. Using this subsample, we found that the gender gap actually becomes slightly larger: girls are 39 percentage points less likely to enter the lottery. However, the coefficient to single-sex schooling is also negative and significant. This suggests that boys in coed schools are more likely to take risks and perhaps 'show off' for the girls (stereotype threat could be causing the gender gap in risk aversion to be larger). Girls in all-girl groups are again more likely to enter the lottery than girls in coed groups.

As a second robustness check, we instrumented for single-sex school attendance using the difference in travel time between an individual's closest coed school and closest single-sex school. To calculate this, we used the six-digit residential postcode for each student. ${ }^{15}$ We broke this variable into two instruments: difference in minutes of travel time if difference in travel time is less than the average; and difference in minutes of travel time if difference in travel time is more than the average. Again we found that the female, single-sex schooling interaction and allgirls group variable are statistically significant. Indeed, the coefficient to the interaction of female with single-sex schooling is slightly larger (see Booth and Nolen, 2012b for further details.)

Given these robustness checks and the continued significance of the all-girls group variable and the single-sex, female interaction, there seems to be strong evidence that girls in same-gender groups enter the lottery more than girls in mixed-gender groups and that girls from single-sex schools enter the lottery more than girls from coed schools. Finally, note that the marginal effects for single-sex girls compared with coed boys ${ }^{16}$ is negative in all columns of Table 1 but they are insignificant, suggesting that single-sex girls choose the risky option as much as boys. However, the size of the coefficient on the all-girls group dummy variable is not large enough to cancel out the negative coefficient on the female dummy variable. Therefore girls in same-gender groups are not entering the lottery as much as coed boys. The length of time a girl

\footnotetext{
${ }^{15}$ We then entered the student's postcode in the 'start' category in MapQuest.co.uk and the school's postcode in the 'ending address' (http://www.mapquest.co.uk/ mq/directions/mapbydirection.do). From this we obtained a 'total estimated time' for driving from one location to the other.

${ }^{16}$ The row denoted "Marginal Effect for Female $=$ Single-Sex = Female * Single-Sex $=1$ " gives the estimated coefficient for the difference between boys from coed schools and girls from single-sex schools.
} 
has been exposed to the same-gender environment - three years on average for girls at singlesex schools and only 30 minutes for girls in single-sex groups - may explain the difference in the size of the effect.

In summary, the results of our real-stakes gamble experiment showed that gender differences in preferences for risk-taking are indeed sensitive to whether the girl attends a single-sex or coed school. Girls from single-sex schools are as likely to choose the real-stakes gamble as boys from either coed or single-sex schools, and more likely than coed girls. That girls in co-educational institutions have a lower preference for risk is interesting, since attending a coed school is the norm for children in many countries, including the UK. Moreover, we found that gender differences in preferences for risk-taking are sensitive to the gender mix of the experimental group, even when these groups are placed within a larger coeducational milieu. In particular, we found that girls are more likely to choose risky outcomes when assigned to all-girl groups. This finding is relevant to the policy debate on whether or not single-sex classes within coed schools could be a useful way forward if the goal is to reduce female levels of riskaversion. $^{17}$

\section{Our second experiment}

\subsection{An overview}

A criticism of Booth and Nolen (2012b) was that assignment to single-sex schools was not random. Although we controlled for non-random selection in a variety of ways, and found our results were not overturned, we decided - with coauthor Lina Cardona-Sosa - to conduct another set of experiments to explore similar issues using random selection into single-sex and coeducational groups, and necessarily using a different subject pool. These results are reported in full in Booth, Cardona-Sosa and Nolen (2013).

In this section we briefly describe the risk results from this second set of experiments. The new experiment did not impose a coefficient of relative risk aversion (CRRA), but instead elicited each subject's CRRA using a series of questions. Our goals in the new study were to see if

\footnotetext{
${ }^{17}$ Booth and Nolen (2012b) also showed how these types of real-states experiments can lead to important findings that may not be present in standard hypotethical lotteries or survey questions.
} 
random assignment to a single-sex group produces effects on individuals' behaviour immediately upon assignment and also after some weeks' exposure to that particular environment (students were required to make choices over real-stakes lotteries at two distinct dates). Our subjects were first year college (university) students entering an Economics or Business degree, whose mean age was 19, and who came from a number of different countries and school types (public and private). Thus we have a different subject pool to that of Booth and Nolen, (2012b). Our 'nurturing' environment is the experimental peer-group or class to which students were randomly assigned by the timetabling office before the start of the academic year. The class groups were of three different types: all-female; all-male; or mixed gender.

Given that the class group was randomly assigned, there are no issues of endogeneity. In the experiment we tested if the experiment environment influences the behaviour under uncertainty of men and women. We were particularly interested in seeing if individuals who are placed in a same-sex group for the experiment make different choices to otherwise identical individuals placed in a mixed group. Our measure of risk aversion involved students making choices over real-stakes lotteries.

\subsection{Subjects, Protocol and Data}

Our subject pool consisted of first year undergraduate students registered for the course, Introduction to Economics, at the University of Essex at the start of the 2010-2011 academic year. Prior to arrival, the students were randomly assigned by the timetabling office to small weekly classes which, during term-time, run in tandem with the lecture course. During their first lecture, students filled in a demographic questionnaire and, as part of a paid experiment during their first class, completed a cognitive ability test and risk questionnaire. Eight weeks later students then took part in another paid experiment by filling in a second risk questionnaire during their class that week. ${ }^{18}$ Students were thus in the economics class environment for one

\footnotetext{
${ }^{18}$ We chose eight weeks apart so that the second experiment would take place in the penultimate week of the tenweek term. Long experience with lecturing in UK universities has taught us that some students head off on their Christmas break a week before term ends. A referee for this survey paper asked why we did not choose to conduct the second risk experiment at the end of the summer (or second term). We chose not to do that because the end of second-term assignments put pressure on students at that time of the year and we wanted to avoid losing students from our sample. However, our paper on academic scores investigates longer-run effects by estimating the impact of our single-sex treatment on exam results (see Booth et al., 2013).
} 
hour per week over eight weeks. At no stage were the students told the purpose of the experiment, what the experiment would involve, nor that it was to be repeated in eight weeks time. All students enrolled in the course are supposed to attend the classes and do the compulsory exercises. Lectures and classes begin immediately after student arrival at campus.

The results from the risk questionnaires form the dependent variable in our empirical analysis, with other information used as controls. Our main interest was whether or not women assigned to all-female classes within a coeducational environment take more risks than those in coeducational classes and if this alters over time. We were also interested in controlling for the impact of cognitive ability, given the recent evidence suggesting that individuals of higher cognitive ability are more likely to take risks, ceteris paribus (see Burks et al, 2009; and Dohmen, Falk, Huffman and Sunde, 2010).

Classes were taught by Graduate Teaching Assistants (GTAs), who were PhD students hired in a competitive hiring process from the pool of PhD applicants. In classes the instructors discuss with students problem-sets that relate directly to the material taught in that week's Introduction to Economics lectures. Students are assigned to specific classes for the Introduction to Economics course, and for that course attend only that class in each week for a period of 20 weeks over the academic year. Booth et al. (2014) describe GTAs' training. The GTAs were not told why we were conducting the experiment or our intended outcome variables. It is therefore highly unlikely that the GTAs would influence students' choices or outcomes. Moreover, GTAs were told not to discuss the experiments or the class arrangements with students. Booth et al. (2014) gives the full set of instructions provided to GTAs and the set of slides they were each required to use in the experiment.

\subsection{Experimental Measures of Risk Aversion}

We used paid experiments to measure subjects' willingness to take risks at two points in time. ${ }^{19}$ In both sessions, students were asked to answer a questionnaire designed to assess subject's risk

\footnotetext{
${ }^{19}$ Session 1 not only involved a 20-minute IQ test and the risk matrix, but also two rounds of two-digit addition (see the experiment protocol in Booth et al, 2013. The only payments involved in Session 1 were for risk or addition. To determine which round was paid, a number was randomly chosen by one of the authors from the set $\{1,2,3\}-$ and where 1 corresponded to the risk questionnaire; 2 to the first round of two-digit addition; 3 to the second round of two-digit addition. If the number 1 were chosen, the student would be paid in accordance with a randomly selected
} 
preferences. This risk questionnaire, shown in Appendix A, follows the format of Dohmen et al. (2010), and consists of 20 rows, each with two columns, A and B. Column A was a 'safe' option: subjects would receive the amount of money stated if they chose the option in column A. The option presented in each row of Column B was a lottery, where individuals had a 50:50 chance of receiving $£ 30$. (At the time of writing, $£ 30$ was worth around US\$48.80.) The safe option in column A started with 0 pounds (first row) and increased until $f 19$ in the final $\left(20^{\text {th }}\right)$ row. Students were asked to make a choice between column A and B in each row (i.e. 20 choices). Subjects were told that a single row would be selected at random if that round were chosen for payment, and that 10 percent of all the participants (also selected at random) would receive the corresponding payment.

A risk-neutral student would choose the lottery up to the point where the safe option offered the same expected value as the lottery (f15). This is where the individual is indifferent between the safe option and the lottery; in our experiment this occurred in row 16. Risk averse students would choose the safe option before row 16 and risk loving students would choose the lottery even after the safe bet of $£ 15$ has been offered. Hence the row where students switched serves as an indicator of risk aversion.

If a student had monotonic preferences then she would have a unique switching point. However nothing prevents them from switching more than once. To account for switching back and forth, we followed Holt and Laury (2002) and used as our dependent variable the number of rows where the student chose the lottery option. Thus our measure of risk aversion is the number of risky choices made by the subject. This measure accounts for the fact that some individuals never switched column (that is, some always chose the risky option or never chose it). In session 1, 70 percent of students switched row only once; 4 percent never switched and 25 percent switched more than once. In session 2, students switching only once account for 73 percent of the sample, 10 percent never switched and 16 percent switched more than once.

row from the risk matrix. If, for that row, the student had chosen the safe outcome she would be paid that, and if she had chosen the risky outcome in column $B$, one of us would flip a coin and the person would be paid based on the outcome. If the number 2 were chosen, the student would be paid 20 pence for each correctly solved problem in that round. If the number 3 were chosen, the student would get paid $£ 1$ for each problem solved correctly in that round if that student was in the top $20 \%$ of performers in this class. Note that if 1 (risk) were randomly chosen, then a random $10 \%$ of people were paid, but if one of the two digit rounds was chosen we paid everyone. 
Table 2: Risky choices across sessions by gender and class composition

\begin{tabular}{|c|c|c|c|c|c|c|c|c|}
\hline & \multicolumn{4}{|c|}{ Women } & \multicolumn{4}{|c|}{ Men } \\
\hline & $\begin{array}{c}\text { First } \\
\text { Session } \\
\text { (1) }\end{array}$ & $\begin{array}{l}\text { Second } \\
\text { Session } \\
\text { (2) }\end{array}$ & $\begin{array}{l}\text { Difference } \\
(2)-(1)=(3)\end{array}$ & $\begin{array}{c}\text { St. error } \\
\text { of (3) }\end{array}$ & $\begin{array}{c}\text { First } \\
\text { Session } \\
\text { (5) }\end{array}$ & $\begin{array}{c}\text { Second } \\
\text { Session } \\
(6)\end{array}$ & $\begin{array}{c}\text { Difference } \\
(6)- \\
(5)=(7)\end{array}$ & St. error of (7) \\
\hline $\begin{array}{l}\text { Single-Sex } \\
\text { Number of risky } \\
\text { choices }\end{array}$ & 10.48 & 12.50 & $2.02^{* *}$ & 0.99 & 12.15 & 13.11 & 0.96 & 0.62 \\
\hline Observations & 44 & 44 & 44 & 44 & 81 & 81 & 81 & 81 \\
\hline $\begin{array}{l}\text { Coed } \\
\text { Number of risky } \\
\text { choices }\end{array}$ & 10.23 & 10.32 & 0.10 & 0.94 & 11.44 & 12.60 & $1.16^{*}$ & 0.65 \\
\hline Observations & 31 & 31 & 31 & 31 & 63 & 63 & 63 & 63 \\
\hline
\end{tabular}
Notes: ${ }^{*}, * *, * *$, corresponds to $10 \%, 5 \%$ and $1 \%$ levels of significance, respectively.

Table 2 shows differences in risky choices, across the two experimental sessions and class-types, for the sample used in the analysis. The first four columns provide information for women, and the last four columns provide information for men, while the top panels give figures for singlesex classes and the bottom panels give figures for coed classes. There are 44 women in allfemale classes and 31 in coeducational classes, while there are 81 men in all-male classes and 63 in coeducational classes. For the all-female classes, the raw data illustrate a significant difference at the 5 percent level across sessions in the mean number of risky choices. Women in all-female classes chose 10.48 risky choices in the first session and 12.50 in the second session conducted eight weeks later. ${ }^{20}$ This compares with women in coeducational classes, who chose 10.23 risky choices in the first session and 10.32 in the second.

From the last four columns of Table 2, it can be seen that young men in all-male classes chose 12.15 risky choices in the first session and 13.11 in the second, a difference that is not statistically significant. However, men in the coeducational class chose 11.44 risky choices in the

\footnotetext{
${ }^{20}$ Assuming a constant relative risk aversion utility function of the type $u(x)=x^{1-\sigma} /(1-\sigma)$, where $\sigma$ is the degree of relative risk aversion, we calculate that the value of $\sigma$ making an individual just indifferent between choosing the lottery and the certain outcome lies between 0.3 and 0.4 . This is similar to the range of 0.3 to 0.5 found by Holt and Laury (2002), and the range of 0.43 and 0.48 found by Dohmen et al. (2010).
} 
first session and 12.60 in the second: this difference is statistically significant, albeit only at the at the 10 percent level. On average, the risk preferences of women in single-sex classes changed the most, followed by men in coeducational classes. Women in the coeducational classes changed the least. (The coeducational classes will form the base in our regressions.)

\section{[Insert Table 3 near here]}

What other controls did we include? Table 3 lists some of them. Appendix Table B at the end of this paper provides the differences in means between single-sex and coed classes. As well as class-type, individual's preferences may be influenced by variables such as subject of study, the gender of the class teacher, cultural factors encapsulated in country-of-origin, the gender environment in high school, and cognitive ability. ${ }^{21}$ How did we measure cognitive ability? In the first session of our experiment we measured IQ using the number of correct answers from a 20minute version of the Raven's Advanced Progressive Matrices, and the mean for this variable is given in Table 3. ${ }^{22}$ The test is a widely accepted indicator of higher order general mental ability. Originally designed to provide information about a subjects' ability using a non-verbal setting uncontaminated by linguistic background, its results have been shown to be consistent across cultures and over time (Raven et al., 1998).

Table 3 shows that our subjects come from a variety of different countries, which are characterised by different cultural norms and levels of gender emancipation. We therefore included the Global Gender Index (GGI) among the controls; a country with a high index is a country with smaller gender gaps in the access to the country' resources regardless the level of resources. Our goal here was not only to see if risky choices are affected by the 'cultural' factors encapsulated in that index, but also to see if the coefficients to our variables of interest alter when we control for gender-relevant cultural factors. As part of the sensitivity analysis we use a

\footnotetext{
${ }^{21}$ To control for whether or not our experimental subjects were exposed to single-sex high-schooling before entering university, we experimented with using, in some specifications, a dummy variable for attending a coed secondary school (where the base was single-sex schooling). These estimates will be discussed later in the paper. Since our experiment includes students from a number of different countries in which single-sex schools were predominantly private, our single-sex secondary schooling will be picking up the influence of both private education and single-sex schooling. Therefore our results are not directly comparable to those of Booth and Nolen (2012b), whose subject pool comprised only students from government-financed secondary schools.

${ }^{22}$ Our distribution of score is skewed to the left. Since normality is not a requirement to standardise the results, we use the z-score of the test as our preferred transformation for the cognitive ability test to facilitate the analysis.
} 
set of dummy variables grouping different nationalities by region-of-origin to control for language and other culture differences. These are Asia (excluding China), Africa, China, Europe, Eastern Europe, and the Asia-Europe boundary, with the English-speaking countries forming the base. $^{23}$

Table 3. Means students attending both sessions

\begin{tabular}{lcc}
\hline & Women $(\mathrm{N}=75)$ & Men $(\mathrm{N}=144)$ \\
\hline Number of risky & & 11.57 \\
choices Session 1 & 10.13 & 0.00 \\
Female & 1.00 & 11.81 \\
Raw score IQ test & 11.60 & 0.02 \\
Z-score IQ test & -0.04 & 0.32 \\
Below the age of 19 & 0.33 & 0.40 \\
Economics Degree & 0.47 & 0.66 \\
Coed School & 0.55 & 0.32 \\
Female Teacher & 0.28 & 0.43 \\
Single sex class & 0.68 & 0.07 \\
Africa & 0.07 & 0.41 \\
English speaking & 0.37 & 0.07 \\
Asia & 0.03 & 0.01 \\
Asia-Europe & 0.01 & 0.15 \\
China & 0.08 & 0.15 \\
East-Europe & 0.23 & 0.14 \\
Europe & 0.21 & 0.71 \\
Gender Gap Index & 0.71 &
\end{tabular}

Notes: Subsample comprises students without missing answers for the two risk experimental sessions. The World Economic Forum's Gender Gap Index (GGI) ranks national gender gaps in economic, political, educational and health aspects. The values for the index go from 0 to 1 .

To measure the initial effect of the class assignment on risk attitudes and its effect over time, we focused on the subset of students taking part in both experiments. Clearly attrition would matter to our econometric analysis if individuals participating in the second session differed in their risk preferences from those who did not. Attrition would also matter if the two samples differed in terms of mean characteristics of the other crucial control variables. For instance, if women assigned to all-female groups were systematically more likely to attend the

${ }^{23}$ English-speaking countries correspond to the UK and North America. Asia (excluding China) also includes countries from the Middle East. Eastern Europe includes Kosovo, Latvia, Lithuania, Poland, Slovakia, Ukraine, Albania, Bulgaria and Romania. The Asia-Europe boundary includes Azerbaijan, Kazakhstan and Russia. 
second session, this might affect our results of interest. We conducted a number of analyses to explore the attrition issue, and reported in Booth et al. (2013). Since these show that attrition is not a problem, we do not discuss these analyses here. The important point to note is that individuals who had made a lot of risky choices in session 1 were as likely to turn up to session 2 as individuals who had made very few risky choices. In other words, people participating in the second session did not differ in their risk preferences from those who did not participate in both sessions.

We now briefly discuss the means of our variables, before turning to the estimates of the determinants of the number of risky choices. Our subjects are all first year students enrolling in Economics 100 or 111 at the University of Essex, who were randomly assigned to a single sex or coeducational class by the central timetabling office at the university. Table 3 reports the variable means for the estimating subsample of students participating in both the 1st and 2nd session. Summing across men and women produces the 219 observations used in our estimation, and 34 percent of this number is female. Notice also that 68 percent of women are in single-sex classes and 43 percent of men. Furthermore, 47 percent of women and 40 percent of men are enrolled in an Economics degree. Even though all our students were taking the introductory economics course, two different formats of the course, EC111 and EC100, were available depending on the degree subject studied (either economics or business-related). The course for students majoring in economics has a higher math component than the course for business and related areas. We therefore control for degree subject in our estimation. Finally, note that the raw IQ score is 11.6 for women and 11.8 for men.

For the sample of 219 students participating in both sessions, we had 16 GTAs teaching 32 classes. Of those 16 GTAs, 5 were female. By design no GTA was perfectly correlated with the treatment. In our GTA allocation we also aimed to ensure, as much as possible, a teacher gender balance across class-types. For further details and for the various ways in which we controlled for potential GTA effects see Booth et al. (2013). In all cases our results were robust to the numerous methods with which we controlled for potential GTA effects. ${ }^{24}$

\footnotetext{
${ }^{24}$ We also estimated an OLS regression of the number of weeks that an individual attended the weekly class in economics, with controls including gender, class-type, degree (economics or business) and the class-teacher's
} 


\subsection{The Results}

Table 4 presents ordinary least squares (OLS) estimates of the determinants of the number of risky choices (which can range between 0 and 20). These are estimated separately for sessions 1 , for session 2 conditioning on the number of risky choices made in session 1, and finally for a model estimating the difference in the number of risky choices across sessions. Column [1] reports the session 1 estimates, while Column [2] show the results for session 2, and Column [3] presents the results for the differenced model. All specifications include 15 GTA dummy variables, one for each GTA. (The base was the GTA who had the most classes. This GTA was male and he taught only coeducational and all-male classes.) We term these GTA fixed effects hereafter. Robust standard errors (SEs), clustered at the module and class level, are reported in parentheses.

Column [1] shows that the randomly assigned class-types have no statistically significant correlation with the number of risky choices in the first session. However, higher ability students do make more risky choices, although the magnitude is quite small: a one standard deviation increase in cognitive ability is associated with an increase of less than half an extra risky choice. Notice also that the impact of the female dummy variable is statistically insignificant. Finally note that students in classes with a female teacher made significantly more risky choices than those with a male teacher, ceteris paribus. The effect is quite large, with the estimated coefficient being 3.29.

gender. The estimated constant in the regression was 6.7, indicating that on average students in our sample attended nearly seven out of eight classes, a respectable number. 
Table 4. OLS estimates of the determinants of number of risky choices

\begin{tabular}{|c|c|c|c|}
\hline & $\begin{array}{c}\text { [1] } \\
\text { Number of } \\
\text { Risky Choices } \\
\text { Session } 1 \\
\end{array}$ & $\begin{array}{c}\text { [2] } \\
\text { Number of } \\
\text { Risky Choices } \\
\text { Session2 } \\
\end{array}$ & $\begin{array}{c}\text { \{3\} } \\
\text { Difference in } \\
\text { Number of } \\
\text { Risky Choices } \\
\end{array}$ \\
\hline Female & $\begin{array}{l}-1.52 \\
(0.96)\end{array}$ & $\begin{array}{l}-1.51 \\
(1.05)\end{array}$ & $\begin{array}{c}-0.54 \\
(1.37)\end{array}$ \\
\hline Risky choices made in Session 1 & - & $\begin{array}{l}0.36^{* * *} \\
(0.08)\end{array}$ & \\
\hline Economics Degree & $\begin{array}{c}0.60 \\
(0.67)\end{array}$ & $\begin{array}{l}-1.21 \\
(0.73)\end{array}$ & $\begin{array}{l}-1.59^{* *} \\
(0.72)\end{array}$ \\
\hline All male class & $\begin{array}{c}1.31 \\
(0.89)\end{array}$ & $\begin{array}{c}0.22 \\
(0.68)\end{array}$ & $\begin{array}{l}-0.61 \\
(0.88)\end{array}$ \\
\hline All female class & $\begin{array}{c}1.14 \\
(1.22)\end{array}$ & $\begin{array}{l}2.62^{* * *} \\
(0.85)\end{array}$ & $\begin{array}{l}1.90^{*} \\
(0.96)\end{array}$ \\
\hline Below the age of 20 & $\begin{array}{l}-0.13 \\
(0.58)\end{array}$ & $\begin{array}{l}-0.66 \\
(0.61)\end{array}$ & $\begin{array}{l}-0.57 \\
(0.76)\end{array}$ \\
\hline Z-score IQ test & $\begin{array}{l}0.48^{* *} \\
(0.20\end{array}$ & $\begin{array}{c}0.33 \\
(0.22)\end{array}$ & $\begin{array}{c}0.03 \\
(0.24)\end{array}$ \\
\hline Constant & $\begin{array}{l}9.63^{* * *} \\
(0.38)\end{array}$ & $\begin{array}{l}9.85^{* * *} \\
(1.01)\end{array}$ & $\begin{array}{l}3.73^{* * *} \\
(0.52)\end{array}$ \\
\hline GTA's Fixed Effects & Yes & Yes & Yes \\
\hline $\begin{array}{l}\text { Observations } \\
R^{2}\end{array}$ & $\begin{array}{c}219 \\
0.164\end{array}$ & $\begin{array}{c}219 \\
0.210\end{array}$ & $\begin{array}{c}219 \\
0.085\end{array}$ \\
\hline Adjusted $R^{2}$ & 0.079 & 0.126 & -0.007 \\
\hline
\end{tabular}

Notes: Dummies for each GTA were included in the analysis. We left out the dummy variable for the GTA with the most students in our estimating sample. Robust standard errors clustered by module and class are reported in parenthesis. ${ }^{*},{ }^{* *}$ and ${ }^{* * *}$, corresponds to $10 \%, 5 \%$ and $1 \%$ levels of significance, respectively

We now turn to the results from session 2, when the risky choices experiment was repeated for the same set of individuals eight weeks later. These estimates are presented in column [2]. In the weeks between Sessions 1 and 2, students have been attending the same classes for the economics course (no switching was permitted), and so they have had a number of weeks' exposure to the sex-composition of the group to which they were randomly assigned. The specification in column [2] estimates the determinants of the number of risky choices in session 2 including a variable that measures the number of session 1 risky choices. Here we see 
that females are less likely to make risky choices, although the coefficient is imprecisely estimated. However, the estimated coefficient to being in an all-female group is large and statistically significant at the one percent level. Women in all-female classes are not only making more risky choices in session 2 than their coed counterparts, but they are also making slightly more risky choices than men - regardless of whether the men are in coed or all-male classes, though, this latter difference is not statistically significant. ${ }^{25}$ Some of the other variables are also statistically significant. Higher ability students continue to make more risky choices.

It is also interesting to consider the magnitude of the estimated coefficient to the variable measuring the session 1 number of risky choices. This coefficient is 0.36 ; and is significantly different from one. If the estimated coefficient to this variable were close to one, we might conclude that the model should be better estimated in first-differenced form. While this is clearly not the case, for the reader's interest we nonetheless undertake this additional exercise, as reported in Coulmn [3]. However, of the two specifications using data from both sessions, column [2] is the preferred model.

In summary our results in Table 4 suggest that on average women are less likely to make risky choices than men at both dates. However, after eight weeks in a single-sex environment, women are significantly more likely to choose the lottery than their counterparts in coeducational groups. These results are robust to the inclusion or exclusion of controls for personality type, as well as a number of other robustness checks, as shown in Booth et al. (2013). ${ }^{26}$

This finding of gender differences in choices under uncertainty is in line with the majority of experimental studies investigating risk choices at a single point in time, as summarized in

\footnotetext{
${ }^{25} \mathrm{~A}$ female in an all female-class is making 2.62-1.51 = 1.11 more risky choices in the second session than a comparable male in a coed class (base group). A man in an all-male class is making 0,22 more risky choices than a comparable male in a coed class.

26 Booth and Nolen (2012b) showed that single-sex schooling for girls had a significantly positive impact on willingness to take risks of 14 year-olds in publicly funded schools. Given this, we experimented with including a dummy variable 'coeducational secondary schooling' as a control in all the regressions reported in Tables 4 (the base is single-sex schooling). This variable was statistically insignificant. Since our second experiment includes students from a number of different countries in which single-sex schools were predominantly private, the base for secondary schooling will be picking up the influence of both private education and single-sex schooling. Therefore our results are not directly comparable to those of Booth and Nolen (20012b), whose subject pool comprised only students from government-financed secondary schools in Britain. Thus, we are not here able to disentangle the private schooling effect from the single-sex schooling effect. Moreover, one may be positively associated with risk attitudes, the other negatively, and this may be why we here find no effect of the combined variable.
} 
Eckel and Grossman (2008) and Croson and Gneezy (2009). ${ }^{27}$ We also found that, in the initial week, the sex composition of the classes into which individuals had been randomly assigned had no impact on the choices over real stakes lotteries. However, after eight weekly sessions in the single-sex class environment, women were significantly more likely to choose the lottery than their counterparts in coeducational groups, and the magnitude of the effect was quite large. No such result was found for men in the single-sex groups. Moreover, our results are robust to the inclusion or exclusion of controls for personality type, as well as to a battery of sensitivity tests reported in the paper.

Our findings are important because they suggest that observed gender differences in behaviour under uncertainty found in many previous studies might actually reflect social learning rather than inherent gender traits. Of course this is not to say that inherent gender traits do not exist. Rather it suggests that they can be modified by the environment in which a woman is placed. In particular, single-sex classes within a coeducational environment were found to significantly alter young women's choices over time.

\section{Conclusions}

The difference in results between Booth and Nolen (2012b) and Booth et al. (2013) lies in the finding that, in the first experiment, the 4-person experimental group to which students were randomly assigned had an immediate effect for all-girls groups, whereas in the second experiment it does not have an effect until the (larger) all-female class has been going for some time. We cannot tell if this is due to the different method used to elicit preferences, the different age-group, the different treatment-group sizes, or the different samples. However, we hope that subsequent work will use the methodology in the present paper to check the external validity of our findings.

How might our results be interpreted? They suggest that a part of the observed gender difference in behaviour under uncertainty found in previous studies might actually reflect social learning rather than inherent gender traits. This is not to say that inherent gender traits do not

\footnotetext{
${ }^{27}$ Harbaugh et al. (2002) find no significant sex differences in risk aversion, although they do find that risk aversion varies with age. Our subjects, however, are all about the same age. Schubert et al. (1999), using as subjects undergraduates from the University of Zurich, show that the context makes a difference. While women do not generally make less risky financial choices than men, they are less likely to engage in an abstract gamble.
} 
exist. Rather it suggests that they can be modified by the environment in which a woman is placed.

Our experiments did not allow us to tease out why these behavioural changes were observed for young women in all-female groups. Conjectures as to the reasons for the changes might include a reduction in stereotype effects. Women, even those endowed with an intrinsic propensity to make riskier choices, may be discouraged from doing so because they are inhibited by culturally-driven norms about the appropriate mode of female behaviour - avoiding risk. Once they are placed in an all-female environment, this inhibition is reduced, and they find it easier to make riskier choices than do women who are placed in a co-ed class.

An alternative but related hypothesis is that being placed, shortly after arrival at university, in an all-female group - even though it is only for one class a week - facilitates the formation of friendships within a faculty environment that is disproportionately male. These friendships may enhance the confidence of the women so placed, and facilitate the formation of work-groups or networks, leading these women to feel more comfortable in making risky choices than women in coed classes.

We hope that future research will not only use the methodology in the present paper to check the external validity of our findings, but will also expand the remit of the research to investigate the underlying causes for the behavioural changes observed in our experiments. 


\section{References}

American Association of University Women, (1992), How Schools Shortchange Girls, American Association of University Women, Washington, DC.

Boheim, R. and Taylor, M. (2002), "Tied down or room to move? Investigating the relationship between housing tenure, employment status and residential mobility in Britain", Scottish Journal of Political Economy 49, 369-92.

Booth, A. L. and H-J Kee, (2011), "A Long-Run View of the University Gender Gap in Australia", Australian Economic History Review 51, 254-276.

Booth, A. L. and P. J. Nolen, (2012a), "Gender Differences In Competition: The Role Of Single-Sex Education", Journal of Economic Behavior and Organisation 81, 542 -555.

Booth, A. L and P. J. Nolen, (2012b), "Gender Differences in Risk Behaviour: Does Nurture Matter?" Economic Journal 122, No. 668, F56-F78.

Booth, A. L and P. J. Nolen, (2012c), "Salience, Risky Choices and Gender", Economics Letters, $117,517-520$.

Booth, A. L., L. Cardona-Sosa and P. J. Nolen, (2013), "Do Single-Sex Classes Affect Exam Scores? An Experiment in a Coeducational University". IZA Discussion Paper No. 7207.

Booth, A. L., L. Cardona-Sosa and P. J. Nolen, (2014), "Gender Differences in Risk Aversion: Do Single-Sex Environments Affect their Development?" Journal of Economic Behavior and Organization, 99, $126-154$.

Bors, D.A. and Stokes, T.L., (1998), "Raven's Advanced Progressive Matrices: Norms for first year university students and the development of a short form", Educational and Psychological Measurement 58, 382-398.

Bowles, S., H. Gintis and M. Osborne, (2001), "The determinants of earnings: a behavioral approach", Journal of Economic Literature 39, 1137-1176.

Brutsaert, H. (1999), "Coeducation and gender identity formation: a comparative analysis of schools in Belgium", British Journal of Sociology of Education 20, 343-53.

Burks S.V., J.P. Carpenter, L. Goette and A. Rustichini, (2009), "Cognitive skills affect economic preferences, strategic behavior, and job attachment", Proceedings of the National Academy of Sciences of the USA 106, 7745-7750.

Charness, G. and PJ Kuhn, (2011), "Lab Labor: What Can Labor Economists Learn from the Lab?" in O Ashenfelter and D Card, eds, Handbook of Labor Economics 4A, pp 229-330, Elsevier.

Coleman, J., (1961), The Adolescent Society, Free Press, New York.

Croson, R. and U. Gneezy, (2009), "Gender differences in preferences", Journal of Economic Literature 47, 1-27.

Datta Gupta, N., A. Poulsen, and M. Villeval, (2005), "Male and Female Competitive Behavior: Experimental Evidence," IZA Working Paper 1833, Nov. 2005. 
Dohmen TJ, A.Falk, D. Huffman and U. Sunde, (2010), “Are Risk Aversion and Impatience Related to Cognitive Ability?" American Economic Review 100, 1238-1260.

Eckel, C., and P. Grossman, (2008), "Men, Women and Risk Aversion: Experimental Evidence”, in C. R. Plott and V. L. Smith, eds., Handbook of Experimental Economics Results, Elsevier Science B.V./North-Holland, Amsterdam, The Netherlands, pp 1078-1086.

Ellison, G., Ashley Swanson, (2010), "The Gender Gap in Secondary School Mathematics at High Achievement Levels: Evidence from the American Mathematics Competitions", Journal of Economic Perspectives 24, 109-128.

Else-Quest, N. M., J. Hyde and M. Linn, (2010), “Cross-National Patterns of Gender Differences in Mathematics: A Meta-Analysis", Psychological Bulletin 136, 103-127

Gneezy, U., K. L. Leonard, and J.A. List, (2009), "Gender Differences in Competition: Evidence from a Matrilineal and a Patriarchal Society", Econometrica 77, 1637-1664.

Gneezy, U., M. Niederle, and A. Rustichini, (2003), "Performance in Comptitive Environments: Gender Differences", Quarterly Journal of Economics 118, 1049--1074.

Gneezy, U. and A. Rustichini, (2004), "Gender and Competition at a Young Age", American Economic Review Papers and Proceedings 94, 377--381.

Goldin, C., L. F. Katz and I. Kuziemko, (2006), "The Homecoming of American College Women: The Reversal of the College Gender Gap", Journal of Economic Perspectives 20, 133-156.

Goldsmith, A.H., J.R., Veum and W. Darity Jr., (1997), "The impact of psychological and human capital on wages", Economic Inquiry 35, 815-829.

Harbaugh, W.T., K. Krause and L. Vesterlund, (2002), "Risk Attitudes of Children and Adults: Choices Over Small and Large Probability Gains and Losses", Experimental Economics 5, 53-84.

Halpmen, D., Eliot, L., Bigler, R., Fabes, R., Hanish, L., Hyde, J., Liben, L., Martin, C. (2011) “The Pseudoscience of Single-Sex Schooling," Science, vol. 333, 23 September, pp. 17061707.

Holt, C. A. and S. K. Laury, (2002), "Risk Aversion and Incentive Effects", The American Economic Review 92(5), 1644-1655.

Kessler, S., D. Ashenden, R. Connell and G. Dowsett, (1985), “Gender relations in secondary schooling", Sociology of Education 58, 34-48.

Maccoby, E. (1998), The Two Sexes: Growing up Apart, Coming Together, Harvard University Press, Cambridge, MA.

Manning, A. and J. Swaffield, (2008), "The gender gap in early-career wage growth", The Economic Journal 118, 983-1024.

Mueller, G. and E. Plug, (2006), "Estimating the effect of personality on male-female earnings", Industrial and Labor Relations Review 60 (1), 3-22. 
National Academy of Sciences, (2006), Beyond Bias and Barriers: Fulfilling the Potential of Women in Academic Science and Engineering, National Academies Press, Washington, D.C.

Niederle, M. and L. Vesterlund, (2007), "Do Women Shy Away From Competition? Do Men Compete Too Much?" Quarterly Journal of Economics, 122 (3) 1067-1101.

Niederle, M. and A. H. Yestrumskas, (2008), "Gender Differences in Seeking Challenges: The Role of Institutions", NBER Working Paper No. 13922, April.

Raven, J., J.C. Raven, and J. H. Court, (1998), Manual for Raven's Progressive Matrices and Vocabulary Scales. Section 4: The Advanced Progressive Matrices, Harcourt Assessment, San Antonio, TX.

Schubert, R., M. Brown, M. Gysler and H.W. Brachinger, (1999), "Financial Decision-Making: Are Women Really More Risk-Averse?” American Economic Review, 89(2), 381-385. 


\section{Appendix A: Risk Questionnaire}

Instructions: Below is a table with 20 rows. In each row there are two choices, one in column $A$ and one in column B. In each row consider your two choices and, when you have decided which option you prefer, you should circle that choice. Pick only one choice for each row; do not discuss your choices with anyone else.

After everyone has chosen their preferred option, the instructor will randomly choose a number 1-20. One out of every 10 people will then get paid for their choice in that row.

For example, if you chose " 50 percent chance of winning $\mathrm{f} 30$ and a 50 percent chance of getting $\mathrm{f0}$ " in row 1 and "1"gets randomly chosen then, if you are one of the 10 percent who get paid, the instructor will flip a coin and you will have a 50 percent chance of winning $£ 30$. If you chose " $£ 0.00$ for sure" in row 1 , though, you will receive $f 0.00$ if " 1 " gets randomly chosen and you are one of the 10 percent who get paid.

Please raise your hand if you have any questions.

\begin{tabular}{|c|c|c|}
\hline Row & Column A & Column B \\
\hline 1 & f0.00 for sure or & $50 \%$ chance of winning $£ 30$ and a $50 \%$ chance of getting $f 0$ \\
\hline & f1.00 for sure or & $50 \%$ chance of winning $£ 30$ and a $50 \%$ chance of getting $f 0$ \\
\hline 3 & $£ 2.00$ for sure or & $50 \%$ chance of winning $£ 30$ and a $50 \%$ chance of getting $f 0$ \\
\hline 4 & $£ 3.00$ for sure or & $50 \%$ chance of winning $£ 30$ and a $50 \%$ chance of getting $£ 0$ \\
\hline 5 & $£ 4.00$ for sure or & $50 \%$ chance of winning $£ 30$ and a $50 \%$ chance of getting $£ 0$ \\
\hline 6 & f5.00 for sure or & $50 \%$ chance of winning $£ 30$ and a $50 \%$ chance of getting $£ 0$ \\
\hline 7 & f6.00 for sure or & $50 \%$ chance of winning $£ 30$ and a $50 \%$ chance of getting $£ 0$ \\
\hline 8 & £7.00 for sure or & $50 \%$ chance of winning $£ 30$ and a $50 \%$ chance of getting $£ 0$ \\
\hline 9 & $£ 8.00$ for sure or & $50 \%$ chance of winning $£ 30$ and a $50 \%$ chance of getting $£ 0$ \\
\hline 10 & £9.00 for sure or & $50 \%$ chance of winning $£ 30$ and a $50 \%$ chance of getting $£ 0$ \\
\hline 11 & $£ 10.00$ for sure or & $50 \%$ chance of winning $£ 30$ and a $50 \%$ chance of getting $f 0$ \\
\hline 12 & $£ 11.00$ for sure or & $50 \%$ chance of winning $£ 30$ and a $50 \%$ chance of getting $f 0$ \\
\hline 13 & £12.00 for sure or & $50 \%$ chance of winning $£ 30$ and a $50 \%$ chance of getting $f 0$ \\
\hline 14 & £13.00 for sure or & $50 \%$ chance of winning $£ 30$ and a $50 \%$ chance of getting $f 0$ \\
\hline 15 & $£ 14.00$ for sure or & $50 \%$ chance of winning $£ 30$ and a $50 \%$ chance of getting $£ 0$ \\
\hline 16 & $£ 15.00$ for sure or & $50 \%$ chance of winning $£ 30$ and a $50 \%$ chance of getting $f 0$ \\
\hline 17 & $£ 16.00$ for sure or & $50 \%$ chance of winning $£ 30$ and a $50 \%$ chance of getting $f 0$ \\
\hline 18 & $£ 17.00$ for sure or & $50 \%$ chance of winning $£ 30$ and a $50 \%$ chance of getting $f 0$ \\
\hline 19 & £18.00 for sure or & $50 \%$ chance of winning $£ 30$ and a $50 \%$ chance of getting $f 0$ \\
\hline 20 & £19.00 for sure or & $50 \%$ chance of winning $£ 30$ and a $50 \%$ chance of getting $f 0$ \\
\hline
\end{tabular}




\section{Appendix B: Table of Means}

Difference in means between students attending coed classes and single-sex classes

\begin{tabular}{|c|c|c|c|c|}
\hline & $\begin{array}{l}\text { Coed classes } \\
\qquad \begin{array}{c}(\mathrm{N}=94) \\
(1)\end{array}\end{array}$ & $\begin{array}{c}\text { Single-sex classes } \\
\qquad(N=125) \\
(2)\end{array}$ & $\begin{array}{c}\text { Diff. in means } \\
(1)-(2)\end{array}$ & $\begin{array}{r}\text { Std. De } \\
(4) \\
\end{array}$ \\
\hline Risky Choices in session 1 & 11.04 & 11.56 & -0.52 & 0.53 \\
\hline Risky Choices in session 2 & 11.85 & 12.90 & $-1.04^{*}$ & 0.57 \\
\hline Female & 0.33 & 0.35 & -0.02 & 0.07 \\
\hline Raw score IQ test & 12.13 & 11.48 & 0.65 & 0.44 \\
\hline Z-score IQ test & 0.13 & -0.08 & 0.20 & 0.14 \\
\hline Below the age of 19 & 0.31 & 0.42 & -0.11 & 0.07 \\
\hline Economics degree & 0.51 & 0.45 & 0.06 & 0.07 \\
\hline Coeducational School & 0.61 & 0.67 & -0.07 & 0.07 \\
\hline \multicolumn{5}{|l|}{ Region of origin } \\
\hline Africa & 0.02 & 0.06 & -0.03 & 0.03 \\
\hline English speaking & 0.35 & 0.29 & 0.06 & 0.06 \\
\hline Asia & 0.05 & 0.06 & -0.01 & 0.03 \\
\hline Asia-Europe & 0.06 & 0.00 & $0.06^{* * *}$ & 0.02 \\
\hline China & 0.12 & 0.22 & $-0.10^{*}$ & 0.05 \\
\hline East-Europe & 0.20 & 0.21 & -0.01 & 0.06 \\
\hline Europe & 0.19 & 0.17 & 0.02 & 0.05 \\
\hline Global Gender Gap Index 2010 & 0.71 & 0.70 & 0.01 & 0.01 \\
\hline Pct. classes attended & 0.83 & 0.84 & -0.00 & 0.03 \\
\hline \multicolumn{5}{|l|}{ Personality Dimensions } \\
\hline 1.Agreeableness & 11.85 & 11.78 & 0.07 & 0.50 \\
\hline 2.Conscientiousness & 12.83 & 12.63 & 0.20 & 0.56 \\
\hline 3.Extraversion & 13.05 & 12.53 & 0.53 & 0.53 \\
\hline 4.Neuroticism & 11.65 & 11.37 & 0.28 & 0.51 \\
\hline 5.Openness & 13.51 & 13.23 & 0.28 & 0.64 \\
\hline Observations & 94 & 125 & & \\
\hline
\end{tabular}

